\title{
Study of the Compressive Strength of Concrete Using Marble, Granite and Recycled Aggregates with Polypropylene Fiber
}

\author{
Rajiv Sonwane \\ M.Tech. Research Scholar \\ Civil Department \\ RKDF College of Engineering \\ Bhopal India \\ rajivsonwane8878@gmail.com
}

\author{
Pushpendra Kumar Kushwaha \\ Assistant Professor \\ Civil Department \\ RKDF College of Engineering \\ Bhopal India
}

pushpendrakush1992@gmail.com

\author{
Jiji M Thomas \\ Assistant Professor \\ Civil Department \\ RKDF College of Engineering \\ Bhopal India
}

\begin{abstract}
Marble Industry produces large amount of waste during mining and processing stages. This waste is dumped on to open land which creates a lot of environmental problems We get recycle aggregate from the old dumped structures and buildings. The main objective of this study was utilization of marble, granite and recycled aggregate waste with polypropylene fiber as a replacement for conventional natural coarse aggregates in concrete. Experimental investigations were carried out to examine the feasibility of use of marble, granite and recycled aggregates waste as coarse aggregates in concrete. Conventional natural coarse aggregates was fully replacement by marble in different percentages $0-60 \%$, granite $0-30 \%$ and recycle aggregates $0-40 \%$ with polypropylene fiber less than $1 \%$ by weight. The concrete formulations were prepared with a constant water.
\end{abstract}

\section{INTRODUCTION}

In the modern era construction Industry is growing very enormously In the modern era construction Industry is grow In the modern era construction Industry is growing very enormously Use of recycled concrete aggregate or other waste materials such as marble coarse, granite coarse and recycled coarse aggregates etc in the production of concrete for the construction of civil structures is a subject matter of significant concern. Mixing of supplementary materials in concrete and mortar affects its compressive strength, workability, and other physical and chemical properties.

Fully replacement of coarse aggregates from marble coarse, granite coarse, recycle coarse aggregates and polypropylene When a matrix is reinforced due to short fibbers, the following improvement can be seen:

$>$ Strengthening of the matrix.

$>$ Fibre bonding and frictional pullout.

$>$ Binding of fibbers across the cracks and crack face stiffness.

$>$ Increase the flexural strength, spilt tensile and compressive strength of concrete.
Polypropylene Fibres added to the concrete improve the parameters of a fresh concrete.

Fibres have a relatively little effect on the compressive strength of concrete before freezing.

Fully replacement of coarse aggregates from marble coarse, granite course, recycle coarse aggregates and polypropylene fiber. By utilizing waste marble and granite and recycled aggregates we are saving Natural aggregates.

This reduction in amount of aggregate further decreases the manufacturing cost and thus reduces the waste emissions. Present analysis allows a 100 percent replacement of Natural aggregates used in the concrete mix when replaced while a watchfully designed mixture of materials.

Recycled coarse aggregates obtained from old demolish concrete structure can be effectively used in manufacturing of concrete similarly waste marble and granite obtained from industries can be used in new concrete,

The following materials are used for the preparation of fiber reinforced concrete.

1. Ordinary Portland cement

2. Fine aggregate

3. Marble coarse aggregate

4. Granite coarse aggregate

5. Recycle coarse aggregate

6. Polypropylene fibber

7. Water

\section{COMPRESSIVE STRENGTH}

Following conclusion can be drawn from results:

- It was observed that compressive strength of concrete tends to increases with Increase in fully replacement percentage of aggregate

- Compressive strength is also increase continuously by Continuous increase marble value up to $40 \%, 50 \%$, and $60 \%$.

- Reducing the amount of granite and polypropylene fibre and granite will increase compressive strength.

- The coarse aggregate can also be replaced by waste marble and recycled material such as demolished concrete waste, however, waste material from marble industry can be used to 
develop numerous properties of concrete. It has been observed from literatures that usually compressive strength increased with addition of waste marble coarse in place of aggregate.

\section{LITERATURE REVIEW}

There have been numerous sources from which Information was gathered but some of them proved to be most useful. Such sources are mentioned as follows:

- IEEE digital library

- Springer's digital library

- Google scholar

- CRAN Repository

- UCI Repository

- DEEP LEARNING Blogs

Professors Guidance and feedback powder as filler in the Polypropylene matrix recommend an interesting opportunity To evaluate the contribution of marble powder in the polypropylene marble composite,

Deepak, GS Dangayash "An investigation on optimization of parameters for injestion molded Polypropylene marble composites with multi objective Genetic Algorithm" IEEE 2016 Deepak Kumar, et.al In the era of sustainability, recycling of Industrial waste materials by using marble In this dissertation various possibilities are provided futilization of waste from different Industries like use of waste marble and granite from respected marble and granite producing Industries .

Allsana Fatima K M, and Shibi Varghese Studied that the strength properties of steel fibber and polypropylene fiber reinforced concrete of $\mathrm{M} 30$ grade with $0 \%, 0.25 \%, 0.5 \%$ and $0.75 \%$ by volume of concrete. Fibre reinforced concrete with crimped steel fibber of $25 \mathrm{~mm}$ length with aspect ratio 50 gives better compressive strength, split tensile strength and flexural strength than hooked end steel fibber $30 \mathrm{~mm}$ length with aspect ratio 50 .

Osman Gence et.al Marble business produces great amount of waste marble which causes environmenlal issues. In paving blocks supported 2 cement sorts we got partially replaced combination with waste marble. Physical and mechanical tests were performed on blocks therefore created.

\section{Sudarshan D. Kore, A.K. Vyas}

Marble industry produces abundant measure of waste mining and preparing stages. This waste is dumped on (o open land which makes a considerable measure of natural issues. The fundamental target of this examination was use of marble squander as a trade of ordinary common coarse aggregates in concrete.

\section{Lal Roshan, Kumar kuldeep}

Studied the strength characteristic of concrete by replacing the natural aggregate with marble and granite recycled aggregate. The experiments has concluded the compressive strength has increases up to $8.7 \%$ by the replacement of $20 \%$ marble and granite waste recycled aggregate.

\section{OBJECTIVE}

The main purpose of this study is to explore the possibility of utilizing waste marble course, granite coarse and recycled coarse aggregate (RCA) concrete in production of concrete.

The main purpose of this study is to explore the possibility of utilizing waste marble course, granite coarse and recycled coarse aggregate (RCA) concrete in production of concrete.

1. To study of the Compressive strength of concrete using marble, granite and recycled aggregates with polypropylene fiber.

2. To investigate the influence of fully replacement of coarse aggregate with marble coarse, granite course and recycle coarse aggregate along with addition of polypropylene fiber.

3. To evolve a systematic methodology for comparing concrete mixes composed using waste materials with original concrete.

4. To find out the suitability of various waste materials in the construction industry.

5. To investigates the effect of replacing basic concrete ingredients with waste materials over a set of properties.

\section{EXPERIMENTAL SETUP AND METHODOLOGY}

This study presents the general description of Parameters considered and testing techniques adopted in the present research

The whole methodology may be divided in different stages of work. The work starts with selection of waste marble, granite and recycled material next stage to perform basic test of materials followed by preparation of specimens and final stage of work to perform test. The following materials are used for the preparation of ftber reinforced concrete.

The following materials are used for the preparation of ftber reinforced concrete.

- Ordinary Portland cement

- Fine aggregate

- Marble coarse aggregate

- Granite coarse aggregate

- Recycle coarse aggregate

- Polypropylene fibber

- Water

MARBLE

Metamorphic Rocks - Introduction, Metamorphism, Common Structures and Textures of Metamorphic Rocks, Classification of Metamorphic Rocks, Descriptive Study of Common Metamorphic Rocks (Quartzite, Marble, Slate, Gneiss, Schist). Classification of Metamorphic Rocks

\section{Classification of Aggregates}

$>$ Natural aggregates

Construction aggregates created from natural sources

like gravel and sand, and extractive merchandise like stone.

\section{$>$ Manufactured aggregates}

Aggregates factory made from handpicked present materials, by-products of Commercial processes or a mixture of those.

\section{> Recycled aggregate Aggregates}

derived from the processing of materials

previously used in a product and in construction.

$>$ Reused

By-product Aggregates produced from by-products of industrial processes.

\section{POLYPROPYLENE FIBER}

Polypropylene fiber concrete is flexible and might be employed in most applications. plastic fibre is additional to the concrete throughout batching. the capability of sturdy structure to resist Weathering action, chemical attack, abrasion and different degradation processes throughout its service life with the 
nominal maintenance is equally vital because the capability of a structure to resist the masses applied thereon.

\section{Properties of Polypropylene Fibers}

1. There is a satirically regular atomic arrangement in the polymer molecule and high crystallinity. Due to regular structure, it is known as isotactic polypropylene.

2. Water demand is no required for polypropylene fibbers.

\section{PREPARATION OF FRESH CONCRETE}

The ingredient of concrete is cement (OPC), fine aggregate (FA), marble coarse, granite coarse, recycle coarse aggregate (RCA), polypropylene fibber and water. Three different proportions of marble course, granite coarse recycle coarse aggregate (RCA) and polypropylene fibber were taken for casting of cube of specimens.

\section{Testing of specimens:}

After the curing of cubes for desired number of days the specimen is taken out of curing tank, wiped out with dry cloth to remove surface water and immediately placed under the testing machine.

\section{Slump Cone Test:-}

This test is conducted to determine the workability of concrete. its apparatus consists of a cone of $10 \mathrm{~cm}$ top diameter, $20 \mathrm{~cm}$ bottom diameter, \& $30 \mathrm{~cm}$ height as shown in fig.3-16. It has two handles for lifting purpose.

Slump cone method is most common method used for measuring the workability and consistency of concrete which can be conducted either in laboratory or site of work. This test is not suitable for very wet and very dry concrete.

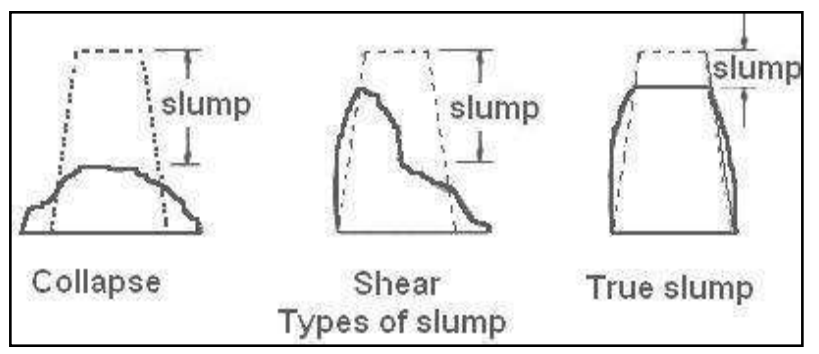

\section{Compressive strength test:}

It is the measure of resistance of hardened concrete towards compression. It is the most important characteristic of concrtc as the concrete structure experiences heavy compression, hence it is very important to determine tolerable limit of compressive load over concret

\section{Granite}

Granite is a type of igneous rock, found on Earth but nowhere else in the Solar System. It is formed from hot, molten magma. Its colour ranges from pink to grey, according to the proportions of its minerals.

The magma cools and converts slowly into solid Stone.

\section{EXPERIMENT RESULT}

The investigation consists of testing of concrete for compression and workability. For testing of compression, three different samples of cube were prepared, each sample consisting of six specimens of cube. Out of these six samples 3 specimens are tested for 7 days compressive test, and 3 specimens are tested for 28 days compressive test.

\section{Slump Cone Test Results}

The slump cone test results carried out on the various specimen of concrete of M25 grade are given in Table and shown in Figure Throughout the research work water - cement ratio kept 0.55 , for the proper workability of the hybrid fiber reinforced concrete.

\section{Analysis of Compressive Strength}

Following Nomenclature was adopted for testing of different types of mixes prepared by Replacement of coarse aggregate by Marble coarse at 40\%, 50\% \& 60, Granite coarse 20\%, 30,\% and $10 \%$, Recycle coarse aggregate $39 \%, 19.25 \%$, \& $29.5 \%$ with Polypropylene fibber $1 \%, 0.75 \% \& 0.5 \%$ byweight of Coarse aggregate.

\section{TYPES OF MIXES}

\begin{tabular}{|c|c|c|c|c|}
\hline & \multicolumn{4}{|c|}{ Replacement Of Coarse Aggregate By (\%) } \\
\hline $\begin{array}{c}\text { Type of } \\
\text { Mix }\end{array}$ & $\begin{array}{c}\text { arable } \\
\text { Coarse }\end{array}$ & $\begin{array}{c}\text { Granite } \\
\text { coarse }\end{array}$ & $\begin{array}{c}\text { Recycle } \\
\text { aggregate }\end{array}$ & Polypropylene \\
\hline & $(\mathrm{Kg})$ & $(\mathrm{Kg})$ & $(\mathrm{Kg})$ & fibber $(\mathrm{Kg})$ \\
\hline MD1 & $40 \%$ & $20 \%$ & $39 \%$ & $1 \%$ \\
\hline MD 2 & $50 \%$ & $30 \%$ & $19.25 \%$ & $0.75 \%$ \\
\hline MD 3 & $60 \%$ & $10 \%$ & $29.5 \%$ & $0.5 \%$ \\
\hline
\end{tabular}

Compressive strength is also increase continuously by Continuous increase marble value up to $40 \%, 50 \%$, and $60 \%$.

$>$ Reducing the amount of granite and polypropylene fibre and granite will increase compressive strength.

$>$ Iterative increase in compressive strength in MD 1, MD2 and MD3.

$>$ Value of Compressive strength after fully replacement of coarse aggregate in MD3 of 7 days will remain same to compressive strength of normal concrete.

Similarly Value of Compressive strength after fully replacement of coarse aggregate in MD3 of 28 days will remain same to compressive strength of normal.

\section{CONCLUSION CAN BE DRAWN FROM RESULTS:}

It was observed that compressive strength of concrete tends to increases with Increase in fully replacement percentage of aggregate

The highest compressive strength of 28 day sample MD 3 was observed almost equal to compared with the control concrete mix (NC). The decreasing percentage of compressive strength of samples MD 1, MD 2, MD 3 are 29.31\%, 20.59\%, and $1.85 \%$ respectively compared with the control concrete $\operatorname{mix}$.

Compressive strength is also increase continuously by Continuous increase marble value up to $40 \%, 50 \%$, and $60 \%$.

- Compressive strength is also increase continuously by Continuous increase marble value up to $40 \%, 50 \%$, and $60 \%$.

- In this research it was observed that, how hybrid fibbers improve the inbuilt properties of concrete as compressive 
strength. Here three different fractions of fibbers were implemented in concrete for improving it Properties.

- Waste materials use in concrete then save the environments. And also save the economically efficient for construction. If we further research in this field it will be helpful to minimize waste from industries and to save environment.

\section{REVIEW}

Introduction: Presents the general background related to the topic of research and thesis.

Abstract : the main objective of this study was utilization of marble, granite and recycled aggregate waste with polypropylene fiber as a replacement for conventional natural coarse aggregates in concrete.

Literature Review This chapter includes summary of various relevant research conducted and published in literature Worldwide.

- Waste marble aggregate and granite by use replacement of natural coarse aggregate and also check compressive strength.

- Recycle aggregate also use to partially replacement of natural aggregate.

- Over the last few decades, there has been a tremendous growth in the study of hybrid reinforced concrete.

Objective The main purpose of this study is to explore the possibility of utilizing waste marble coarse, granite coarse and recycled coarse aggregate (RCA) concrete in production of concrete.

Methodology This chapter presents the general description of Parameters considered and testing techniques adopted in the present research.

\section{EXPERIMENTAL INVESTIGATION}

The whole experimental methodology is completed in various stages. Determining the Compressive strength of reinforced concrete by adding steel and for the glass fibers in different proportions. So the entire methodology can be spit in following major categories for the execution of work which is corresponded to flow chart.

\section{RESULT}

\section{Slump Cone Test Results}

The slump cone test results carried out on the various specimen of concrete of M25 grade Throughout the research work water cement ratio kept 0.55 , for the proper workability of the hybrid fiber reinforced concrete From the.

\section{Analysis of Compressive Strength}

Following Nomenclature was adopted for testing of different types of mixes prepared by Replacement of coarse aggregate by Marble coarse at 40\%, 50\% \& 60, Granite coarse 20\%, 30,\% and $10 \%$, Recycle coarse aggregate $39 \%, 19.25 \%$, \& $29.5 \%$ with Polypropylene fibber $1 \%, 0.75 \% \& 0.5 \%$ byweight of coarse aggregate.

Results shows that fully replacement of coarse aggregate with waste marble coarse, granite coarse, recycle coarse aggregate and polypropylene fibber at MD 3 of weight of a aggregate shows maximum compressive strength in the experiment as compared to Different percentage in marble coarse, granite coarse, recycle coarse aggregate and polypropylene fibber replacement of aggregate .
Percentage variation Waste materials recycle aggregate and fibbers in mix

\begin{tabular}{|c|c|c|c|c|}
\hline & \multicolumn{3}{|c|}{ Replacement Of Coarse Aggregate By (\%) } \\
\hline $\begin{array}{c}\text { Type of } \\
\text { Mix }\end{array}$ & Marble & Granite & Recycle & Polypropylene \\
\hline & Coarse & coarse & aggregate & fibber (Kg) \\
\hline MD 1 & $40 \%$ & $20 \%$ & $39 \%$ & $1 \%$ \\
\hline MD 2 & $50 \%$ & $30 \%$ & $19.25 \%$ & $0.75 \%$ \\
\hline MD 3 & $60 \%$ & $10 \%$ & $29.5 \%$ & $0.5 \%$ \\
\hline
\end{tabular}

Slump Cone Test Results

\begin{tabular}{|c|c|c|c|c|}
\hline S.N. & SAMPLE 3 & $\begin{array}{c}\text { Percentage } \\
(\%)\end{array}$ & \multicolumn{2}{|c|}{$\begin{array}{c}\text { Slump value } \\
(\mathrm{mm})\end{array}$} \\
\hline 1 & Marble Coarse & $60 \%$ & $65 \mathrm{~mm}$ & $70 \mathrm{~mm}$ \\
\hline 2 & Granite Coarse & $10 \%$ & & \\
\hline 3 & $\begin{array}{c}\text { Recycle Coarse } \\
\text { Aggregate }\end{array}$ & $29.5 \%$ & & \\
\hline 4 & Polypropylene Fibrc & $0.5 \%$ & & \\
\hline
\end{tabular}

7 Day Compressive Strength

\begin{tabular}{|c|c|c|c|c|c|}
\hline & $\begin{array}{c}\text { Type } \\
\text { of }\end{array}$ & Weight & $\begin{array}{c}\text { Average } \\
\text { weight }\end{array}$ & $\begin{array}{c}\text { Compressive } \\
\text { strength }\end{array}$ & $\begin{array}{c}\text { Average } \\
\text { compressive }\end{array}$ \\
\hline & Mix & $(\mathrm{kg})$ & $(\mathrm{kg})$ & $\left(\mathrm{N} / \mathrm{mm}^{\wedge} 2\right)$ & strength \\
\hline & & & & & $\left(\mathrm{N} / \mathrm{mm}^{\wedge} 2\right)$ \\
\hline & & 7 Day & 7 Day & 7 Day & 7 Day \\
\hline 1 & & 8.407 & & 18.08 & \\
\hline 2 & MD 3 & 8.530 & 8.52 & 18.26 & 18.38 \\
\hline 3. & & 8.630 & & 18.8 & \\
\hline
\end{tabular}

Concrete cube compressive strength (7days) 28 Day Compressive Strength

\begin{tabular}{|c|c|c|c|c|c|}
\hline S.N. & $\begin{array}{c}\text { Type of } \\
\text { Mix }\end{array}$ & $\begin{array}{c}\text { Weight } \\
(\mathrm{kg})\end{array}$ & $\begin{array}{c}\text { Average } \\
\text { weight } \\
(\mathrm{kg})\end{array}$ & $\begin{array}{c}\text { Compressive } \\
\text { strength } \\
\left(\mathrm{N} / \mathrm{mm}^{\wedge} 2\right)\end{array}$ & $\begin{array}{c}\text { Average } \\
\text { compressive } \\
\text { strength } \\
\left(\mathrm{N} / \mathrm{mm}^{\wedge} 2\right)\end{array}$ \\
\hline & & 28 Day & 28 Day & 28 Day & 28 Day \\
\hline 1 & & 8.13 & & 23.73 & \\
\hline 2 & MD 1 & 8.17 & 8.18 & 26.17 & 24.33 \\
\hline 3 & & 8.25 & & 23.11 & \\
\hline
\end{tabular}



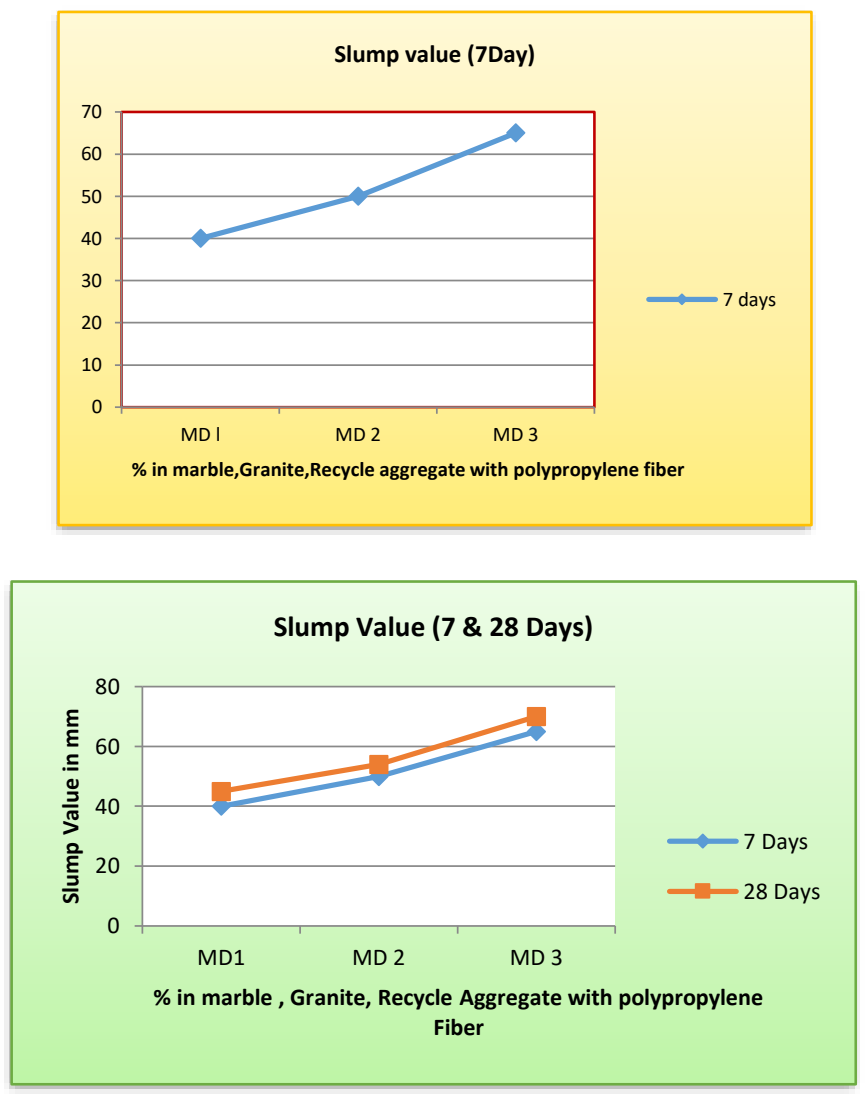

\section{CONCLUSION}

D Waste marble aggregate and granite by use replacement of natural coarse aggregate and also check compressive strength.

$>$ Recycle aggregate also use to partially replacement of natural aggregate.

$>$ Over the last few decades, there has been a tremendous growth in the study of hybrid reinforced concrete.

$>$ It is clear that the concept of hybridizing fibbers is a sound one and significant

$>$ Improvements have been reported by various investigations.

> Varieties of fibbers such as polypropylene and steel were successfully used as hybrid for the fabrication of composites.

$>$ When fibbers added in certain percentages in the concrete improve the strain properties as well as crack resistance, ductility and toughness.

Experimental investigation usefulness of marble coarse granite coarse, Recycle coarse aggregate and Polypropylene fibber as construction material was investigated. Various concrete cubes have been casted using these materials to investigate compressive strength. Slump values were also examined.

\section{REFERENCES}

[1] Allabdo All A., Elmoaty Abd, Elmoaty M. Abd, Esraa M. Auda "Re-use of waste marble dust in the production of cement and concrete". Construction and Building Materials, Volume 50, 15 January 2014, Pages 28-41, ISSN 0950-061.

[2] Anna Kotwa "The replacement of the parts of the aggregate in concrete with Chalcedonite powder- Procedia Engineering, Volume 195, 2017.

[3] Antonia andre, Jorge de brito, Alexandra rosa, Diogo pedro "Durability performance of concrete incorporating coarse aggregate from marble industry waste", Journal of cleaner production, Volume 65, Feb 2014.

[4] Bashar S. Mohammed, M. Abudullahi ,C.K. Hoong " Statistical models for concrete containing wood chipping as partial replacement to fine aggregate" Construction and Building Material, Volume 55, 2014.

[5] B.T. Ashwini, Manjunath "Partial replacement of E- Plastic waste as coarse aggregate in concrete" Procedia Environmental Science, Volume 35, 2016.

[6] Bartolomeo Coppola , Luc Courard , Frederic Michel, Loredana Incarnato, Luciano Di Maio "Invenstigation on the use of formed plastic waste as natural aggregates replacement in light weight mortar" Composites parts B Engineering, Volume 99, 2016.

[7] "Composite utilizing residues of marble and granite for building popular homes" Journal of building Engineering, Volume 9, 2017.

[8] Deepak, GS Dangayash "An investigation on optimization of parameters for injestion molded Polypropylene marble composites with multi objective Genetic Algorithm" IEEE 2016 